\title{
anatomy
}

Original Article

\section{Factors affecting foot arch development in Northern Ethiopia}

\author{
Belta Asnakew Abegaz, Dereje Gizaw Awoke \\ Department of Human Anatomy, College of Medicine and Health Sciences, Bahir Dar University, Babir Dar, Ethiopia
}

\begin{abstract}
Objectives: Bones of the foot form longitudinal and transverse arches which absorb and distribute downward forces from the body during standing and moving on different surfaces. The medial longitudinal arch is the longest, highest and most important in static position and moving. Studies classify the medial longitudinal arch as high, normal, and flat. This study was designed to determine the factors that affect the development of the medial longitudinal foot arch.

Methods: Cross-sectional study design was employed, 424 subjects were selected using quota sampling method. The footprint areas were measured using a planimeter. Descriptive statistics and multiple logistic regressions were used for data analysis and $p$ value $<0.05$ was considered as statistically significant.

Results: From the total subjects, $46.2 \%, 42.9 \%$, and $10.9 \%$ were high, normal and flat arched, respectively. About $6.9 \%$ of shoe-wearers and $4 \%$ of the barefooted had flat arch. From the flat arched, $8.5 \%$ were males and $2.4 \%$ were females. Among the shoe-wearers, $10.2 \%$ used closed toe shoes, and 3.3\% that wore sandals were flat-arched. From 29 flat-arched, $24(11.2 \%)$ were urban residents.

Conclusion: Sex, type of shoes, wearing shoes and being barefooted residence were significant factors affecting the development of foot arch. Shoe age did not determine arch development.
\end{abstract}

Keywords: barefooted; foot arch; planimeter; shoe-wearers; type of shoe

Anatomy 2017;11(1):26-29 @2017 Turkish Society of Anatomy and Clinical Anatomy (TSACA)

\section{Introduction}

One of the important and most variable characteristics of the foot is the height of the medial longitudinal arch (MLA) above the ground plane during weight bearing activity. ${ }^{[1]}$ The human foot has three arches: the medial longitudinal, lateral longitudinal, and transverse (anterior). From these the MLA is the longest, the highest, and the most important of the three during static support of the body and protect the foot from injury during movement. ${ }^{[2,3]}$

According to arch index (AI) or the height of MLA when $\mathrm{AI}<0.21$ is high arch, $0.21<\mathrm{AI}<0.26$ is normal arch, and $\mathrm{AI}>0.26$ is low (flat) arch. ${ }^{[1]}$ There are factors that affect the development of foot arch such as improper shoe wearing, the type of shoes a child wears, residence and being overweight etc. ${ }^{[4,5]}$ Children are born with flat feet, MLA slowly develops during childhood usually by about age five or six. ${ }^{[6,7]}$

There are some studies conducted about the factors affecting the development of foot arch in America, Iran,
India, Saudi Arabia, and Nigeria. As far as we know, there is no similar study conducted in Ethiopia. Therefore, the current study was designed to determine the factors affecting foot arch development in Ethiopia.

\section{Materials and Methods}

Cross-sectional study design was employed for this study. The study subjects were selected by quota sampling method. A total 424 subjects from the study area were selected; their age ranged from 15 to 65 years, 207 were male and 217 were female subjects who had no foot deformity and lower limb injuries. Ethical approval was obtained from ethical review board of local authorities. Official letters were submitted to the district officials, explaining the purpose and the importance of the study and permission was obtained from each. Confidentiality was maintained at all levels of the study.

Various techniques have been proposed to evaluate foot arch types, each of them have their own limita- 
tions. ${ }^{[8-10]}$ Foot print parameter is better than other parameters, because it is inexpensive, easy for handling, effective for individual and population based investigations. ${ }^{[10]}$ Studies show there is no difference between the right and left foot prints. ${ }^{[1]]}$ Therefore, we took only the right footprint. The footprints were collected using two smooth wooden plates, normal wall paint, brush, and a sheet of paper in which on its other side the questionnaire was printed. One of the wooden plates impregnated with the paint for capturing the footprints and the subjects put their footprints on the other wooden plate on which the sheet of paper was placed.

Row data were checked for clarity, consistency, accuracy and were analyzed using IBM SPSS (Statistical Package for the Social Sciences, version 16.0; IBM, Chicago, IL, USA) software. Descriptive analysis was done for basic demographic characteristics. Pearson's chi square test was used as a statistical test, and multiple logistic regressions were employed for analyzing the data. Thus, in multivariate analysis, the association between independent and outcome variables was expressed by odds ratio (OR) with $95 \%$ CI.

Arch index is the ratio of the area of the middle third of the foot print area to the footprint area excluding the toes. The area of the footprint was first measured using a planimeter and the AI was calculated with the formula: AI $=\mathrm{B} / \mathrm{A}+\mathrm{B}+\mathrm{C} \cdot{ }^{[1]}$ The three regions of the footprint areas are leveled as hind foot (A), mid foot (B), and fore foot (without the toe) (C) (Figures $\mathbf{1}$ and 2). High arch was defined as $\mathrm{AI}<0.21$, normal arch $0.2 \mathrm{I}<\mathrm{AI}<0.26$, and low arch (flat) $\mathrm{AI}>0.26 .^{[1,8]}$

\section{Results}

From the total 424 study subjects, 207 (48.8\%) were males and $217(51.2 \%)$ were females. $215(50.7 \%)$ were shoewearers and $209(49.3 \%)$ were barefooted. The mean age of the subjects was $25.86 \pm 8.7$ with median 23 and ranged from 15 to 65 years. The mean arch measurement was $0.198 \pm 0.06$, area ratio with median 0.21 and ranged from $0-0.35$ area ratio (Table $\mathbf{1}$ ).

From 215 shoe-wearers $6.9 \%$ were flat-arched, and from 209 barefooted $4 \%$ were flat-arched. There was a significant association between wearing shoes and being barefooted (odds ratio (OR): 1.617; 95\% confidence interval (CI): 1.209-1.819) (Tables 2 and 4). The prevalence of flat arch was more common in males, whereas high arch was more common in female subjects. From all male subjects, $36(8.5 \%)$ had flat arch, 10 (2.4\%) of female subjects had flat arch, while 79 (18.6\%) males and 117 (27.6\%) females were high-arched. (OR: 6.698; 95\% CI: 3.123-14.351) (Tables 2 and 4 ).

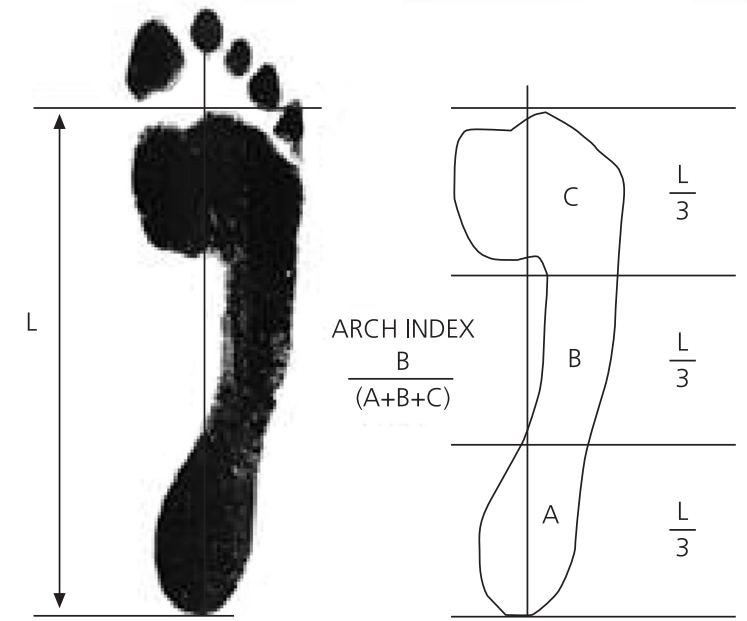

Figure 1. Measurement of arch index (Al). The three regions of the footprint areas are leveled as hind foot (A), mid foot (B), and fore foot (C) (excluding the toe). L: lenght of the footprint area excluding the toe.

From the total 215 shoe-wearers, $38(17.7 \%)$ and 59 (27.4\%) high arched were males and females, respectively. This shows that high arch is more prevalent in females than in males. Of the total 29 flat-arched individuals, 23 $(10.7 \%)$ were males and only $6(2.8 \%)$ were females. Male individuals were 7.4 times more likely to have flat arch than females (OR: 7.47; 95\% CI: 2.57-21.72). There was a statistically significant association between sex and flat arch development (Tables 2 and 4). About 22 (10.2\%) and $7(3.3 \%)$ were flat-arched individuals who wore closed toe and sandals, respectively. There was a significant relationship between shoe type and flat arch (OR: 6.576; 95\% CI: 2.391-18. 092). Closed toe shoe-wearers were 6.57 times flat arched than those who wore sandals (Tables 3 and 4).

A total of 54 (25.1\%) urban and $43(20 \%)$ rural residents had high foot arch. Of the flat-arched individuals, 24
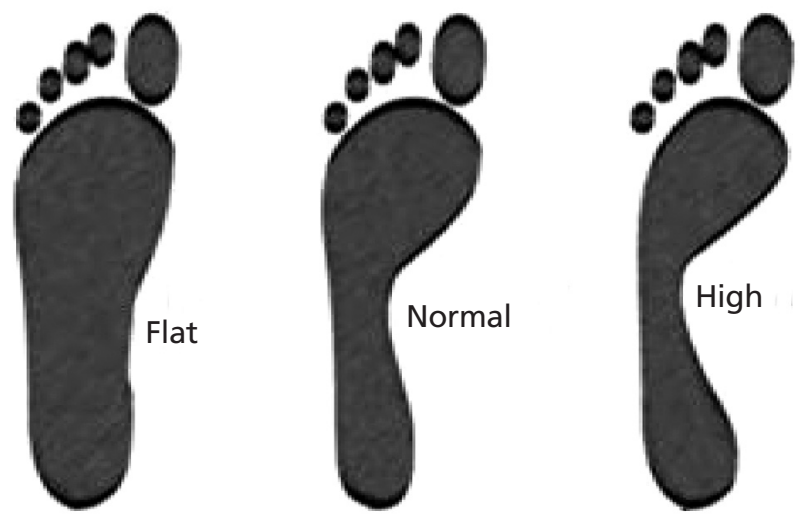

Figure 2. Sample of the three types of foot arch. 
Table 1

The study subjects with their variables.

\begin{tabular}{llcc}
\hline Variable & & Number & Percentage (\%) \\
\hline \multirow{2}{*}{ Shoe condition } & Shoe-wearer & 215 & 50.7 \\
& Barefooted & 209 & 49.3 \\
Age & $15-24$ & 258 & 60.8 \\
& $25-34$ & 116 & 27.4 \\
& $35-44$ & 28 & 6.6 \\
Arch type & $45-54$ & 9 & 2.1 \\
& $55-65$ & 13 & 3.1 \\
& High & 196 & 46.2 \\
Barefooted & Normal & 182 & 42.9 \\
& Flat & 46 & 10.9 \\
Shoe-wearer & Males & 100 & 47.8 \\
& Females & 109 & 52.2 \\
& Males & 107 & 49.8 \\
& Females & 108 & 50.2 \\
\hline
\end{tabular}

(11.2\%) were urban and 5 (2.3\%) were rural residents. This indicated that the prevalence of flat arch was common in urban residents than the rurals. Hence, the subjects who lived in urban residences had 4.3 times flat foot than those who lived in rural areas (OR: 4.350; 95\% CI: 1.388 13.629) (Tables 3 and 4).

There is no consistency in the relationship between shoe-wearing age and arch types. There might be other factors, such as the type of shoes the individual used to wear during childhood, and the duration of wearing shoes (Table 3).

\section{Discussion}

The results of this study showed there is no difference in the prevalance of flat foot in various age groups (Table 3). A study performed in India also showed no statistical significant difference in the prevalence of flat feet in various age groups screened, indicating significant variations in the prevalence do not occur with increasing age after skeletal maturity. ${ }^{[12]}$ As a result, the age of the subjects was not considered as a determining variable of the study.

For both shoe-wearers and barefooted, male subjects had higher tendency to have flat arch than females; the reverse was true for high arch (Tables 2 and 4). Similar results were recorded in a study done India and Austria showing that the boys had a significant higher tendency for flat foot than the girls: the prevalence of flat foot was $52 \%$ in boys and $36 \%$ in girls $(\mathrm{p}<0.01)$. Boys had a significantly higher tendency for flat feet than girls, and high arch was more common in women than in men. ${ }^{[12-14]}$

In this study, wearing shoes promoted the prevalence of flat arch than being barefooted (Tables 2 and 4). A study
Table 2

Variables (both barefooted and shoe-wearer) with their arch type.

\begin{tabular}{llccc}
\hline \multirow{2}{*}{ Variable } & & \multicolumn{3}{c}{ Arch type } \\
\cline { 3 - 5 } Sex & & High & Normal & Flat \\
& Males & $79(18.6 \%)$ & $92(21.7 \%)$ & $36(8.5 \%)$ \\
Shoe condition & Females & $117(27.6 \%)$ & $90(21.2 \%)$ & $10(2.4 \%)$ \\
& Shoe-wearer & $97(22.9 \%)$ & $89(21 \%)$ & $29(6.9 \%)$ \\
Shoe-wearer & Barefooted & $99(23.3 \%)$ & $93(21.9 \%)$ & $17(4 \%)$ \\
& Males & $38(17.7 \%)$ & $46(21.4 \%)$ & $23(10.7 \%)$ \\
Barefooted & Females & $59(27.4 \%)$ & $43(20 \%)$ & $6(2.8 \%)$ \\
& Males & $41(19.6 \%)$ & $46(22 \%)$ & $13(6.2 \%)$ \\
& Females & $58(27.8 \%)$ & $47(22.5 \%)$ & $4(1.9 \%)$ \\
\hline
\end{tabular}

Table 3

Shoe-wearer variables with their arch type distribution.

\begin{tabular}{llccc}
\hline \multirow{2}{*}{ Variable } & & \multicolumn{3}{c}{ Arch type } \\
\cline { 3 - 5 } & & High & Normal & Flat \\
\hline \multirow{2}{*}{ Residence } & Urban & $54(25.1 \%)$ & $48(22.3 \%)$ & $24(11.2 \%)$ \\
& Rural & $43(20 \%)$ & $41(19.1 \%)$ & $5(2.3 \%)$ \\
Shoe age & $1-9$ years & $49(22.8 \%)$ & $34(15.8 \%)$ & $15(7 \%)$ \\
& Age $\geq 10$ years & $48(22.3 \%)$ & $55(25.6 \%)$ & $14(6.5 \%)$ \\
\multirow{2}{*}{ Shoe type } & Closed toe & $26(12.1 \%)$ & $32(14.9 \%)$ & $22(10.2 \%)$ \\
& Sandals & $71(33 \%)$ & $57(26.5 \%)$ & $7(3.3 \%)$ \\
\hline
\end{tabular}

Table 4

Multiple logistic regression analysis of variables associated with adult arch type (for shoe-wearer subjects only).

\begin{tabular}{llcc}
\hline Variable & & Crude OR (95\% Cl) & Adjusted OR (95\% Cl) \\
\hline Sex & $\begin{array}{l}\text { Females* } \\
\text { Males }\end{array}$ & $5.952(2.219,15.964)$ & $7.477(2.573,21.727)^{\dagger}$ \\
\multirow{2}{*}{ Residence } & $\begin{array}{l}\text { Rural* } \\
\text { Urban }\end{array}$ & 1 & 1 \\
Shoe type & $\begin{array}{l}\text { Closed toe* } \\
\text { Sandals }\end{array}$ & $8.822(1.346,10.851)$ & $4.350(1.388,13.628)^{\dagger}$ \\
& Sand (3.280, 22.457) & $6.576(2.391,18.092)^{\dagger}$ \\
\hline
\end{tabular}

*Reference category; ${ }^{\dagger} p<0.05 . \mathrm{Cl}$ : confidence interval, OR: odds ratio.

conducted in India also supported the idea that the prevalence of flat arch was more significant among those who wear shoes. The incidence among children who used footwear was $8.6 \%$ compared with $2.8 \%$ in those who did $\operatorname{not}(\mathrm{p}<0.001) .{ }^{[15]}$

The prevalence of flat feet in urban residents was found 4.3 times higher than those in rural dwellers (Tables 3 and 4). With similar results, another study from Saudi Arabia concluded that residents in urban areas were significantly associated with double the risk of flat feet (OR: 2.04; 95\% CI: $1.1-3.48){ }^{[4]}$ 
The result of the present study showed no statistically significant difference between early shoe wearing and late shoe wearing for the prevalence of flat arch (Table 3), in contrast with earlier studies. However, a more recent study done in India concluded that the incidence of flat feet was $3.24 \%$ among those who started to wear shoes before the age of 6 years, $3.27 \%$ in those who started between the age of $6-15$ years, and $1.75 \%$ in those who first wore shoe at the age of $16(\mathrm{p}<0.001){ }^{[12]}$ This difference was due to type of shoe and the duration the subjects wore shoe in childhood that resulted in reducing the prevalence of flat feet in early shoe-wearers. ${ }^{[15]}$

Wearing closed toe shoe is a significant factor for the development of flat arch (Tables 3 and 4). This was confirmed in many studies showing that the prevalence of flat arch also varied with the type of the foot wear. ${ }^{[15]}$ In more specific terms, closed toe shoes inhibited the development of the arch of the feet more than slippers and sandals did. The type of usual footwear during childhood was a significant predictor for the development of flat foot. Considering cases that went barefooted during childhood as the reference category, those who wore shoes during their early childhood were at double the risk of having flat foot (adjusted OR: 2.18; 95\% CI: 1.01-5.73)..$^{[4,12,15]}$

\section{Conclusion}

The results showed that the person's age and shoe wearing age were not the determining factors for the arch types. Wearing closed toe shoe, being urban resident and male negatively affected the development of thr MLA. In addition, being barefooted, rural resident, female, and wearing sandals promoted the development of the MLA.

\section{Acknowledgements}

The authors would like to acknowledge Asegedech Bekele ( $\mathrm{PhD}$, Associate Professor) of Human Anatomy at the College of Medicine and Health Sciences, University of Gondar for her professional, technical and academic advice.

\section{References}

1. Cavanagh PR, Rodgers MM. The arch index: a useful measure from foot print. J Biomech 1987;20:47-51.

2. Chang YW, Hung W, Wu HW, Chiu YC, Hsu HC. Measurement of foot arch in standing, level of walking, vertical jump and Sprint start. International Journal of Sport and Exercise Science 2010;2: 31-8.

3. Xiong S, Goonetilleke RS, Witana CP, Weerasinghe TW, Au EY. Foot arch characterization: a review, a new metric, and a comparison. J Am Podiatr Med Assoc 2010;100:14-24.

4. Abdel-Fattah MM, Hassanin MM, Felembane FA, Nassaane MT. Flat foot among Saudi Arabian army recruits: prevalence and risk factors. East Mediterr Health J 2006;12:211-7.

5. Daneshmadi H, Rahnema N, Mehdizadeh R. Relationship between obesity and flat foot in high school boys and girls. International Journal of Sports Science and Engineering 2009;3:43-9.

6. Mortazavi SMJ, Espandar R, Baghdadi T. Flatfoot in children: how to approach? Iran J Pediatr 2007;17:163-70.

7. Eluwa MA, Omini RB, Kpela T, Ekanem TB, Akpantah AO. The incidence of pes planus amongst Akwa Ibom State Students in the University of Calabar. The Internet Journal of Forensic Sciences 2008;3:1-5.

8. Shiang TY, Lee SH, Lee SJ, Chu WC. Evaluating different footprint parameters as a predictor of arch height. IEEE Eng Med Biol Mag 1998;17:62-6.

9. Lin CH, Lee HY, Chen JJ, Lee HM, Kuo MD. Development of a quantitative assessment system for correlation analysis of footprint parameters to postural control in children. Physiol Meas 2006;27: 119-30.

10. Hernandez AJ, Kimura LK, Laraya MHF, Favaro E. Calculation of Staheli's plantar arch index and prevalence of flat feet: a study with 100 children aged 5-9 years. Acta Ortop Bras 2007;15:68- 71.

11. Chu WC, Lee SH, Chu W, Wang TJ, Lee MC. The use of arch index to characterize arch height: a digital image processing approach. IEEE Trans Biomed Eng 1995;42:1088-93.

12. Sachithanandam V, Joseph B. The influence of footwear on the prevalence of flat foot: a survey of 1846 skeletally mature persons. J Bone Joint Surg Br 1995;77:254-7.

13. Dunn JE, Link CL, Felson DT, Crincoli MG, Keysor JJ, McKinlay JB. Prevalence of foot and ankle conditions in a multiethnic community sample of older adults. Am J Epidemiol 2004;159:491-8.

14. Pfeiffer M, Kotz R, Ledl T, Hauser G, Sluga M. Prevalence of flat foot in preschool-aged children. Pediatrics 2006;118:634-9.

15. Roa UB, Joseph B. The influence of footwear on the prevalence of flat foot: a survey of 2300 children. J Bone Joint Surg Br 1992;74:525-7.

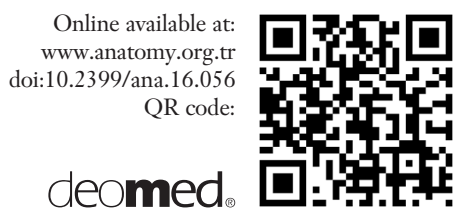

Correspondence to: Belta Asnakew Abegaz, MSc
Department of Human Anatomy, College of Medicine and Health Sciences,
Bahir Dar University, Bahir Dar, Ethiopia
Phone: +251918 789549
e-mail: asbelta21@gmail.com
Conflict of interest statement: No conflicts declared.

This is an open access article distributed under the terms of the Creative Commons Attribution-NonCommercial-NoDerivs 3.0 Unported (CC BY-NCND3.0) Licence (http://creativecommons.org/licenses/by-nc-nd/3.0/) which permits unrestricted noncommercial use, distribution, and reproduction in any medium, provided the original work is properly cited. Please cite this article as: Abegaz BA, Awoke DG. Factors affecting foot arch development in Northern Ethiopia. Anatomy 2017;11(1):26-29. 